\title{
Algorithm Apriori Association Rule in Determination of Fuzzy Rule Based on Comparison of Fuzzy Inference System (FIS) Mamdani Method and Sugeno Method
}

\author{
Muhammad Fadli Arif (Corresponding author) \\ Mathematic Department, Faculty of Mathematics and Natural Sciences, Universitas \\ Brawijaya 65145 Malang, Jawa Timur, Indonesia \\ Tel: 62-856-4003-4936Ｅ-mail: mufadliarif@hotmail.com \\ Bima Anoraga \\ Mathematic Department, Faculty of Mathematics and Natural Sciences, Universitas \\ Brawijaya 65145 Malang, Jawa Timur, Indonesia
}

\begin{abstract}
Samingun Handoyo
Mathematic Department, Faculty of Mathematics and Natural Sciences, Universitas Brawijaya
\end{abstract}

65145 Malang, Jawa Timur, Indonesia

\section{Harisaweni Nasir}

Faculty of Civil Engineering, University Teknologi Malaysia 81310 Skudai, Johor, Malaysia

Tel: 60-137-092-210Ｅ-mail: harisaweni@gmail.com

Received: December 14, 2015 Accepted: January 10, 2016 Published: May 3, 2016

doi:10.5296/bms.v7i1.9410 URL: http://dx.doi.org/10.5296/bms.v7i1.9410 


\section{Abstract}

The economic stability of a country can be determined from the changes in the rate of inflation. Inflation is measured by the annual percentage change in the Consumer Price Index. Since there exists some uncertainties in the inflation data, fuzzy logic is one of the ways to analyse the data. Decisions in fuzzy logic can be made using the fuzzy rule-based inference system. Fuzzy rule-based inference can be obtained from expert knowledge, but the knowledge from the experts on the working of a system is not always available. Therefore, the use of association rules approach could solve the problem. Using three methods of fuzzy inferences; namely the Mamdani Methods, zero-order Sugeno method, and the first-order Sugeno method, this study was carried out to determine which method fits to predict the general monthly inflation data in Indonesia. The Inflation data were derived from the inflation of foodstuff price, $X_{1}$; inflation of food, drinks, cigarettes and tobacco prices, $X_{2}$; inflation of housing, water, electricity, gas, and fuel prices, $X_{3}$; inflation of clothing price, $X_{4}$; inflation of health care price, $X_{5}$; inflation of education, recreation, and sports prices, $X_{6}$; and inflation of transportation, communication, and financial services prices, $X_{7}$. The performance of the three methods was compared using mean squared error (MSE) and mean absolute percentage error (MAPE) as the accuracy measurement to establish the best fuzzy inference method that fits the inflation value. It was found that the most appropriate method which generated the most accurate results to fit the fuzzy inference system to the inflation data was the first-order Sugeno method.

Keywords: Apriori algorithm, Association rule, Fuzzy inference system, Mamdani, Sugeno, Inflation 


\section{Introduction}

One of the indicators of a country's economic stability is the consumer price index as it contributes significantly to the changes in the inflation rate. High inflation rate will result in the decrease of people's buying power (Hidayat, 2010). Therefore, it is necessary to find the right forecasting method that fits the general inflation data based on the consumer price index figures from different commodity groups.

The existence of uncertainties in the inflation data can be remedied by fuzzy logic which is one of the methods often used to analyze data with uncertainties. By using fuzzy logic, the rate of inflation could be more easily understood and interpreted. According to Naba (2009), fuzzy logic is defined as a logic that has a value of vagueness or ambiguity between right and wrong simultaneously. The level of truth depends on the weight of its membership. One of the advantages of the theory of fuzzy logic is its process of reasoning ability in language.

Fuzzy logic was finally accepted as an emerging technology in the late 1980s after having been viewed as a controversial theory for two decades. Fuzzy logic has been accepted due to its nature which is closer in spirit to human thinking and natural language as compared to conventional logical system. Different to the control using fuzzy logic, classical control theory is based on the mathematical models that describe the physical plants under consideration (Mohandas, 2001). The essence of fuzzy control is to build a model of a human expert who is capable of controlling the plant without thinking in terms of a mathematical model (Sandhu, 1997). Fuzzy systems are very useful in two general contexts: first, in situations involving highly complex systems whose behaviors are not well understood, and second, in situations where an approximate but fast solution is warranted (Ross, 2009).

Decision making in fuzzy logic is performed by using the inference system. Fuzzy Inference System (FIS) is the process of mapping the input space into the output chamber using fuzzy logic. The process of the FIS is divided into four stages, which are fuzzification, fuzzy rule-based formation, inference systems or fuzzy reasoning, and defuzzification.

FIS has been successfully developed in many areas such as, automatic control, data classification, decision analysis, forecasting data and expert system (Setiadji, 2009). The modelling techniques based on FIS are appealing and have found many successful applications in various fields including Fuzzy PID position control approach in computer numerical control machine tool (Zhao, 2013); research on real-time simulation and control of linear 1-stage inverted pendulum (Song, 2013); as well as on a study on the control methods based on 3-DOF helicopter model (Gao, 2012; Wang, 2014).

There are several methods to see if fuzzy logic fits the inflation data. The methods include the Mamdani method and the Sugeno method. Mamdani method was introduced by Ebraham Mamdani to build the control system from steam engine. Mamdani's method uses some IF-THEN rules which take precedents from experienced experts in the field. This method was developed based on the research that was conducted by Lotfi A. Zadeh (1973) about fuzzy algorithm for complex system and was commonly used for decision making. 
Sugeno FIS method was first introduced in 1965 by Takagi-Sugeno-Kang. FIS using the Sugeno method has the characteristic that is consequently not in the form of fuzzy rules of fuzzy sets, but instead, in the form of a constant or linear equations with variables in accordance with its input.

Sugeno FIS is similar to Mamdani FIS in many aspects, but is quite different in the consequent part. Sugeno FIS uses a mathematical function of the input as a rule consequent, while Mamdani uses fuzzy set as a rule consequent. Due to the different forms in the rule consequent of Mamdani and Sugeno FISs, the methods used in both types of FIS to obtain the overall crisp output are different too. The consequent of a rule in a Sugeno is normally a polynomial in the input variables, but it can be of any type of functions as long as it can properly present the output within the fuzzy space specified by the antecedent. The Sugeno FIS resulted from a first-order polynomial was originally proposed in Takagi (1985) on Fuzzy identification of systems and its applications to modelling and control, and continued on Structure identification of fuzzy model by Sugeno itself in 1988. Fuzzy sets and systems are called a first-order Sugeno FIS (Wang, 2014).

The difference between Mamdani and Sugeno FIS is that the Mamdani has a membership functions output whereas Sugeno has no output of membership functions. The design system of Mamdani is less flexible as compared to Sugeno method as the last one can optimize the output by integrating with the ANFIS (Kaur, 2012). The most fundamental difference between Mamdani and Sugeno is in the way of the crisp output is generated from the fuzzy inputs. Sugeno uses weighted average to compute the crisp output; while Mamdani uses the technique of defuzzification of a fuzzy output. The expressive power and interpretability of Mamdani output is lost in the Sugeno FIS since the consequents of the rules are not fuzzy (Haman, 2008).

Fuzzy rule based system is usually derived from the knowledge possessed by an operator or an expert on the workings of the system. In addition, fuzzy rule based can be derived from the combination of the set of fuzzy variables, but it is not often that the expert knowledge of the workings of a system is available. As a result, the rules of a system could not be found; hence the fuzzy inference system could not be done. Therefore the Association rules approach is used.

Since it was discovered by Rakesh Agrawal in 1993, the Association rules has always been the focus of research in various fields such as data mining and artificial intelligence (Gopalan, 2009). The purpose of the Association rules is to find a pattern of a collection of data by using rules that associate the data with other data. Association rules is defined as a process to find the associative rules that meet the minimum requirements for the minimum support and the minimum requirements for confidence (minimum confidence) in the database (Utomo, 2010). The Association rules is used to discover patterns by using rules that associate the data with other data.

Comparison of Mamdani and Sugeno method has been made in their ability to predict the 
magnitude of the rate of inflation. In previous researches, the basic rules used fuzzy based solely on a combination of variable fuzzy sets, hence the results are less satisfactory (Zufa, 2013; Moon 2013).Therefore, in this study, the same data and method will be used. However, with the basic rules of fuzzy derived from the Association rules method used, it is hoped the results fit the prediction more accurately.

\section{Methodology}

\subsection{Method Analysis}

Each fuzzy set can be expressed by a membership function. There are several ways to express the fuzzy set membership functions. For the universe to discrete usually used to register, namely members of the universe are listed along with their membership degrees. For continuous infinite universe, the most commonly used method is the analytical way to represent the membership functions of fuzzy sets in question in the form of a mathematical formula that can be presented in graphical form. For example $\tilde{\mathrm{A}}$ is a fuzzy set "Real numbers which are close to $2 "$. Ã then can be presented as

$$
\tilde{\mathrm{A}}=\int_{\mathrm{x} \in \mathrm{R}} \mathrm{e}^{-(\mathrm{x}-2)^{2}} / \mathrm{x}
$$

Where $\mu_{\tilde{A}}(x)=\mathrm{e}^{-(x-2)^{2}}$ is a membership function of $\tilde{A}$

Most fuzzy set in the universe is the set of all real numbers with the membership function expressed in the form of a mathematical formula (Susilo, 2003). $\in \mathrm{R}$ represents the GBell membership function which is a fuzzy set with three parameters namely $\gamma, \beta$ and $\alpha$ It can be expressed as GBell $(\mathrm{x} ; \alpha, \beta, \gamma)$ if it fulfills:

$$
\operatorname{GBell}(X ; \alpha, \beta, \gamma)=\frac{1}{1+\left|\frac{x-(\gamma)}{\alpha}\right|^{2(\beta)}}
$$

Where $\gamma$ is the centre of the curve, whereas $\beta \alpha$ is the width of the slope at the cross point of the GBell membership function.

$$
\text { IF } x \text { is } A \text { THEN } y \text { is } B
$$

with $\mathrm{x}$ and $\mathrm{y}$ being the scalar, while A and B are fuzzy sets. The proposition IF is called the antecedents while the proposition THEN is called the consequent. This proposition can be expanded using fuzzy operators such as (Cox, 1994):

$$
\text { IF }\left(x_{1} \text { is } A_{1}\right) \cdot\left(x_{2} \text { is } A_{2}\right) \bullet \ldots . .\left(x_{n} \text { is } A_{n}\right) \text { THEN } y \text { is } B
$$


With • being the operators such as OR/AND.

There are two numbers which are used to determine the degree of an uncertainty in an Association rules, namely the support and the confidence. Support is a measure that indicates a large degree of dominance of an item of the overall transaction, while confidence is a measure that indicates a relationship between two or more items which are conditional. Both sizes are very useful in determining the Association Rules, which will be compared with a predetermined limit. These limits consist of minimum support and minimum confidence.

$$
\text { Support, } \mathrm{S}(\mathrm{A} \rightarrow \mathrm{B})=\frac{(\mathrm{AuB})}{\mathrm{N}}
$$

Where:

$(\mathrm{A} \cup \mathrm{B})=$ total itemset in all transactions

$\mathrm{N}=$ the total number of transactions

$$
\text { Confidence, } \mathrm{C}(\mathrm{A} \rightarrow \mathrm{B})=\frac{(\mathrm{AUB})}{(\mathrm{A})}
$$

Where:

$(\mathrm{A} \cup \mathrm{B})=$ Total itemset in all transactions

(A) = Number of antecedent transactions

Apriori algorithm is an algorithm that was introduced by Ramakrishnan Srikant and Rakesh Agrawal in 1994. The purpose of Apriori algorithm is to find frequent itemsets in a set of data. At iteration $\mathrm{k}$ will find all itemsets that have $\mathrm{k}$ items, called the $\mathrm{k}$-itemset. The main properties of Apriori algorithm are all subsets of a frequent itemsets which is also a member of frequent itemsets.

Apriori algorithm uses iterative approach, in which k-itemsets are used to investigate the $(\mathrm{k}+$ 1) -itemset. The steps of the algorithm are as follows:

1. Set $\mathrm{k}=1$ (refer to the itemset to-1).

2. Calculate all k-itemsets (itemsets that have k-item).

3. Calculate the support of all the candidate itemset. Selection is based on the minimum itemset support her.

4. Combine all k-sized itemsets to generate candidate $(k+1)$-itemset.

5. Set $\mathrm{k}=\mathrm{k}+1$ (refer to the itemset to-2 and so on).

6. Repeat steps 3-5 until there are no more large itemset can be formed. 
A final set of itemset is formed by creating a composite of all k-item. The multiple linear regression equation is then formed as consequent of the fuzzy rule based (First-order Sugeno) with regression parameter estimation using the least squares method. Multiple linear regression equation is expressed as follows (Draper and Smith, 1992):

$$
Y_{i}=\beta_{0}+\beta_{1} X_{1 i}+\beta_{2} X_{2 i}+\ldots \ldots+\beta_{k} X_{k i}+\varepsilon_{i}
$$

Fuzzy basic rules are the rules that are built in the form of functions implication that states the relationship between the input variables to the output variables. In general, the form of the model rules of Takagi-Sugeno-Kang use the IF-THEN rules. According to Cox (1994), there are two models for Sugeno FIS, namely:

a. Zero-order Sugeno Fuzzy Model

$$
\text { IF }\left(\mathrm{X}_{1} \text { is } \mathrm{A}_{1}\right) \cdot\left(\mathrm{X}_{2} \text { is } \mathrm{A}_{2}\right) \cdot \ldots \cdot\left(\mathrm{X}_{\mathrm{n}} \text { is } \mathrm{A}_{\mathrm{n}}\right) \text { THEN } \mathrm{Z}=\mathrm{k}
$$

b. First-order Sugeno order Fuzzy Model

$$
\text { IF }\left(\mathrm{X}_{1} \text { is } \mathrm{A}_{1}\right) \cdot\left(\mathrm{X}_{2} \text { is } \mathrm{A}_{2}\right) \cdot \ldots \cdot\left(\mathrm{X}_{\mathrm{n}} \text { is } \mathrm{A}_{\mathrm{n}}\right) \text { THEN }
$$

$Z=p_{1} * x_{1}+p_{2} * x_{2}+\ldots+p_{n} * x_{n}+q$

Meanwhile, the basic rule of fuzzy inference for Mamdani method can be expressed as:

$$
\text { IF } \left.\left(\mathrm{X}_{1} \text { is } \mathrm{A}_{1}\right) \cdot\left(\mathrm{X}_{2} \text { is } \mathrm{A}_{2}\right) \cdot \ldots \cdot\left(\mathrm{X}_{\mathrm{n}} \text { is } \mathrm{A}_{\mathrm{n}}\right) \text { THEN ( } \mathrm{z} \text { is } \mathrm{B}\right)
$$

Where $A_{n}$ is a fuzzy set functioning as the antecedents, $B$ is a fuzzy set is the consequent, $p_{n}$ is a constant to-n and $q$ is constant in the consequent (Cox, 1994). The application of process rules (functions implications) is done by calculating the value of $\alpha$-predicate (fire strength) of each rule and continued with the composition rules. The last stage of the fuzzy inference is the defuzzification.

Defuzzification is a result of the conversion of numbers in the fuzzy inference process in the form of crisp numbers. Defuzzification on Mamdani FIS is obtained using the centroid method.

$$
Z^{*}=\frac{\int_{Z} z_{\mu(Z) d Z}}{\int_{Z} \mu(Z) d Z}
$$




$$
Z^{*}=\frac{\sum_{j=1}^{n} z_{j} \mu\left(z_{j}\right)}{\sum_{j=1}^{n} \mu\left(z_{j}\right)}
$$

Composition of the rules on the method of Sugeno defuzzification is done using a weighted average (weighted average). The defuzzification can be expressed as follow:

$$
Z^{*}=\frac{\sum_{i=1}^{n} w_{i} Z_{i}}{\sum_{j=1}^{n} w_{i}}
$$

Where $Z_{i}$ is an output at the consequent basic rule to-i, $W_{\mathrm{i}}$ is the result of the operation on the antecedents of fuzzy sets and $n$ is a number of rules used (Naba, 2009).

$\widehat{Y}_{i} Y_{i}$ Effectiveness in conducting fittings need to be known. The effectiveness can be checked by knowing the error that has been generated from the results of such fittings. There are several different methods to evaluate the error that has been generated from the result of fitting such as the Mean Square Error (MSE) and the Mean Absolute Percentage Error (MAPE). If $Y_{i}$ is the actual data for the period-i and $\widehat{Y}_{i}$ is a prediction for the same period, then the mistake (error) is defined as:

$$
e_{i}=Y_{i}-\hat{Y}_{i}
$$

The accuracy of a model in conducting fittings can be measured by calculating the MSE, i.e. the mean squared error. MSE is calculated by the formula:

$$
M S E=\frac{\sum_{i=1}^{n} e_{i}^{2}}{n}
$$

Where :

$e_{i}^{2}=$ error

$n \quad=$ number of observation

MAPE is a measure of the relative accuracy which is used to determine the deviation percentage of the predicted results. MAPE is calculated by the formula:

$$
M A P E=\frac{\sum_{i=1}^{n}\left|\left(\frac{\varepsilon_{i}}{Y_{i}}\right) \times 100 \%\right|}{n}
$$




\section{Macrothink}

The smaller values of MSE and MAPE indicate that the method has better fitting accuracy.

\subsection{Research Data}

The data used in this research are the secondary data, monthly inflation data and the monthly consumer price index based on seven categories of goods and services. The data used is Indonesian inflation data by groups of commodities (goods and services) which were taken from the official web Indonesian Central Statistics Agency (www.bps.go.id). Formation of fuzzy sets (fuzzification) on the monthly general inflation data of Indonesia according to commodity groups was performed using the input and output variables. The input and output variables of the fuzzy inference systems are:

- General Inflation (Y)

- Inflation of foodstuffs price $\left(\mathrm{X}_{1}\right)$

- Inflation of food, beverages, cigarettes and tobacco prices $\left(\mathrm{X}_{2}\right)$

- Inflation of housing, water, electricity, gas and fuels prices $\left(\mathrm{X}_{3}\right)$

- Inflation of clothing price $\left(\mathrm{X}_{4}\right)$

- Inflation of health care price $\left(\mathrm{X}_{5}\right)$

- Inflation of education, recreation and sports prices $\left(\mathrm{X}_{6}\right)$

- Inflation of transportation, communication and financial services rates $\left(\mathrm{X}_{7}\right)$

In which each variable consists of 5 fuzzy set, namely: Low, Low Enough, Medium, High Enough and High.

Input and output variables are divided into two categories, namely the training data and the testing data. The training data are used to form the basis of fuzzy rules which are derived from the Association rules, multiple linear regression equation and the FIS. Meanwhile, the testing data are used to test the fitting accuracy obtained from the Mamdani FIS and Sugeno FIS. All the data were used in the training process, of which $30 \%$ of them were used for data testing, which were collected on monthly basis of the general inflation in Indonesia by commodity groups. Sharing of the training data and the testing data is as follows:

$$
\begin{aligned}
& \text { Data }_{\text {training }}=\frac{100}{100} \times 104=104 \\
& \text { Data }_{\text {testing }}=\frac{30}{100} \times 104=31
\end{aligned}
$$

After fitting fuzzy model of each method it can be seen that the method is more accurate in predicting the magnitude of the rate of general inflation month to month Indonesia, namely 


\section{Macrothink}

by looking at the value of the smallest MSE and MAPE of each method. Fuzzy inference method that has the smallest MSE and MAPE is a fuzzy inference method is more appropriate in the fitting accuracy of the model.

\section{Result}

The first stage in forming an FIS involved the process of determining the fuzzy variables and universe of discourse. The universe of discourse of each fuzzy variable was obtained by determining the range of the Indonesian inflation data by group commodities from 2006 to 2014. The universe of discourse for each fuzzy variable is shown in Table 1.

Table 1. Determination of fuzzy variable and their respective universe of discourse

\begin{tabular}{|c|c|c|}
\hline Function & Fuzzy variable & $\begin{array}{c}\text { Universe of } \\
\text { discourse }\end{array}$ \\
\hline \multirow{7}{*}{ Input } & Inflation of foodstuff price, $X_{1}$ & {$[-2,885,46]$} \\
\hline & $\begin{array}{l}\text { Inflation of food, beverage, } \\
\text { cigarette, and tobacco prices, } X_{2}\end{array}$ & {$[0,132,02]$} \\
\hline & $\begin{array}{l}\text { Inflation of housing, water, } \\
\text { electricity, gas, and fuels prices, } \\
X_{3}\end{array}$ & {$[-0,061,80]$} \\
\hline & Inflation of clothing price, $X_{4}$ & {$[-1,703,07]$} \\
\hline & Inflation of health care price, $X_{5}$ & {$[0,061,88]$} \\
\hline & $\begin{array}{l}\text { Inflation of education, recreation, } \\
\text { and sports prices, } X_{6}\end{array}$ & {$[-0,284,77]$} \\
\hline & $\begin{array}{l}\text { Inflation of transportation, } \\
\text { communication, and financial } \\
\text { services rates, } X_{7}\end{array}$ & {$[-2,749,60]$} \\
\hline Output & General inflation, $Y$ & {$[-0,353,29]$} \\
\hline
\end{tabular}

Variable $X_{1}$ has a universe of discourse ranging between $-2.88 \%$ and $5.46 \%$, variable $X_{2}$ between $0.13 \%$ and $2.02 \%$, variable $X_{3}$ between $-0.06 \%$ and $1.80 \%$, variable $X_{4}$ between $-1.70 \%$ and $3.07 \%$, variable $X_{5}$ between $0.06 \%$ and $1.88 \%$, variable $X_{6}$ between $-0.28 \%$ and $4.77 \%$, and variable $X_{7}$ between $-2.74 \%$ and $9.60 \%$. From these universe of discourse, the final output variable, i.e. the general inflation, $Y$, has a universe of discourse ranging from 
$-0.35 \%$ to $3.29 \%$.

In this study, the input data consists of seven variables. The domains include low fuzzy set; low-enough fuzzy set; medium fuzzy set; high-enough fuzzy set; and high fuzzy set, which were derived from the universe of discourse. The classification of fuzzy sets was based on decision of the researcher because there was no special condition that formed the basis of determining the number of fuzzy sets for the researcher working on the fitting using fuzzy logic.

The value or degree of a membership is calculated using the membership functions method. In this study, the fuzzy set membership functions were represented by the g-bell membership functions. The values of the center point, width, and slope at the cross points of the g-bell membership function are listed in Table 2.

Table 2. Values of the center point, width, and slope at the cross points of the g-bell membership functions

\begin{tabular}{|l|c|c|c|c|}
\hline \multirow{2}{*}{ Fuzzy Variable } & Fuzzy Set & $\begin{array}{c}\text { Center } \\
\text { Point }\end{array}$ & Width & Slope \\
\hline \multirow{2}{*}{$\begin{array}{l}\text { Inflation of } \\
\text { foodstuff price, } \\
\boldsymbol{X}_{\boldsymbol{I}}\end{array}$} & $\mathrm{L}$ & $-2,88$ & 1,043 & 2,5 \\
\cline { 2 - 5 } & $\mathrm{M}$ & $-0,795$ & 1,043 & 2,5 \\
\cline { 2 - 5 } & $\mathrm{HE}$ & 3,375 & 1,043 & 2,5 \\
\cline { 2 - 5 } & $\mathrm{H}$ & 5,46 & 1,043 & 2,5 \\
\hline \multirow{2}{*}{$\begin{array}{l}\text { Inflation of } \\
\text { food, beverage, } \\
\text { cigarette, and } \\
\text { tobacco prices, } \\
\boldsymbol{X}_{2}\end{array}$} & $\mathrm{~L}$ & 0,13 & 0,2363 & 2,5 \\
\cline { 2 - 5 } & $\mathrm{M}$ & 0,6025 & 0,2363 & 2,5 \\
\cline { 2 - 5 } & $\mathrm{HE}$ & 1,547 & 0,2363 & 2,5 \\
\hline \multirow{2}{*}{\begin{tabular}{l} 
Inflation \\
\hline
\end{tabular}} & $\mathrm{H}$ & $-0,0600$ & 0,2325 & 2,5 \\
\hline
\end{tabular}




\begin{tabular}{|c|c|c|c|c|}
\hline \multirow{4}{*}{$\begin{array}{l}\text { housing, water, } \\
\text { electricity, gas, } \\
\text { and fuel prices, } \\
X_{3}\end{array}$} & LE & 0,405 & 0,2325 & 2,5 \\
\hline & $\mathrm{M}$ & 0,87 & 0,2325 & 2,5 \\
\hline & $\mathrm{HE}$ & 1,335 & 0,2325 & 2,5 \\
\hline & $\mathrm{H}$ & 1,8 & 0,2325 & 2,5 \\
\hline \multirow{5}{*}{$\begin{array}{l}\text { Inflation of } \\
\text { clothing price, } \\
X_{4}\end{array}$} & $\mathrm{~L}$ & $-1,7$ & 0,5962 & 2,5 \\
\hline & LE & $-0,5075$ & 0,5962 & 2,5 \\
\hline & $\mathrm{M}$ & 0,685 & 0,5962 & 2,5 \\
\hline & HE & 1,877 & 0,5962 & 2,5 \\
\hline & $\mathrm{H}$ & 3,07 & 0,5962 & 2,5 \\
\hline \multirow{5}{*}{$\begin{array}{lr}\text { Inflation } & \text { of } \\
\text { health } & \text { care } \\
\text { price, } X_{5} & \end{array}$} & $\mathrm{~L}$ & 0,05999 & 0,2275 & 2,5 \\
\hline & LE & 0,515 & 0,2275 & 2,5 \\
\hline & $\mathrm{M}$ & 0,9701 & 0,2275 & 2,5 \\
\hline & HE & 1,425 & 0,2275 & 2,5 \\
\hline & $\mathrm{H}$ & 1,88 & 0,2275 & 2,5 \\
\hline \multirow{5}{*}{$\begin{array}{l}\text { Inflation of } \\
\text { education, } \\
\text { recreation, and } \\
\text { sports prices, } X_{6}\end{array}$} & $\mathrm{~L}$ & $-0,2933$ & 0,6312 & 2,5 \\
\hline & LE & 0,9826 & 0,6312 & 2,5 \\
\hline & M & 2,245 & 0,6312 & 2,5 \\
\hline & $\mathrm{HE}$ & 3,507 & 0,6312 & 2,5 \\
\hline & $\mathrm{H}$ & 4,77 & 0,6312 & 2,5 \\
\hline Inflation of & $\mathrm{L}$ & $-2,74$ & 1,543 & 2,5 \\
\hline
\end{tabular}




\begin{tabular}{|l|c|c|c|c|}
\hline $\begin{array}{l}\text { transportation, } \\
\text { communication, }\end{array}$ & $\mathrm{LE}$ & 0,345 & 1,543 & 2,5 \\
\cline { 2 - 5 } $\begin{array}{l}\text { and financial } \\
\text { services rates, } \\
\boldsymbol{X}_{7}\end{array}$ & $\mathrm{M}$ & 3,43 & 1,543 & 2,5 \\
\cline { 2 - 5 } & $\mathrm{HE}$ & 6,515 & 1,543 & 2,5 \\
\cline { 2 - 5 } & $\mathrm{H}$ & 9,567 & 1,543 & 2,5 \\
\hline \multirow{2}{*}{$\begin{array}{l}\text { General } \\
\text { inflation, } \boldsymbol{Y}\end{array}$} & $\mathrm{L}$ & $-0,35$ & 0,455 & 2,5 \\
\cline { 2 - 5 } & $\mathrm{LE}$ & 0,56 & 0,455 & 2,5 \\
\cline { 2 - 5 } & $\mathrm{M}$ & 1,47 & 0,455 & 2,5 \\
\cline { 2 - 5 } & $\mathrm{HE}$ & 2,38 & 0,455 & 2,5 \\
\cline { 2 - 5 } & $\mathrm{H}$ & 3,29 & 0,455 & 2,5 \\
\hline
\end{tabular}

The g-bell membership functions were used to represent the low fuzzy set, low-enough fuzzy set, medium fuzzy set, high-enough fuzzy set, and high fuzzy set. For example, the calculation for $X_{l}$ is as follows:

$$
\begin{aligned}
& \mu_{\text {low }}=B(X ; 1,043 ; 2,5 ;-2,88) \mu_{\text {high enough }}=B(X ; 1,043 ; 2,5 ; 3,375) \\
& \mu_{\text {low enough }}=B(X ; 1,043 ; 2,5 ;-0,795) \mu_{\text {high }}=B(X ; 1,043 ; 2,5 ; 5,46) \\
& \mu_{\text {medium }}=B(X ; 1,043 ; 2,5 ; 1,29)
\end{aligned}
$$

The formation of rules in the association rules method is influenced by the size of the minimum support and minimum confidence. At the beginning of the process, the 527 rules established by the antecedents and consequents were not yet in accordance with the provisions of the rule-based feature in FIS modeling. All these rules were then simplified according to said provisions that classified the input variables as antecedents and output variables as consequents, generating 52 rules only with predetermined minimum support and minimum confidence. The rules produced by the association rules method are summarized in Table 3. 
Table 3. Rules produced by the association rules method

\begin{tabular}{|c|c|c|c|c|c|}
\hline No & Lhs & Rhs & Support & Confidence & Lift \\
\hline 1 & $\left\{X_{l}=\mathrm{LE}\right\}$ & $\{\mathrm{Y}=\mathrm{L}\}$ & 0.3365385 & 0.9459459 & 1.967568 \\
\hline 2 & $\begin{array}{l}\left\{X_{1}=\mathrm{M},\right. \\
\left.X_{3}=\mathrm{LE}\right\}\end{array}$ & $\{\mathrm{Y}=\mathrm{L}\}$ & 0.1057692 & 0.8461538 & 1.955556 \\
\hline • & & & & & \\
\hline - & & & & & \\
\hline - & & & & & \\
\hline 52 & $\begin{array}{l}\left\{X_{1}=\mathrm{LE},\right. \\
X_{2}=\mathrm{L}, \\
X_{3}=\mathrm{L}, \\
X_{5}=\mathrm{L}, \\
X_{6}=\mathrm{L}, \\
\left.X_{7}=\mathrm{LE}\right\}\end{array}$ & $\{\mathrm{Y}=\mathrm{L}\}$ & 0.1250000 & 1.0000000 & 2.080000 \\
\hline
\end{tabular}

According to Table 3, Rule 1 has the support value of 0.3365385 , which indicates that Indonesia's general monthly inflation rate for variable $X_{1}$ contains LE set while variable $Y$ includes the L set. Rules 1 also has the confidence value of 0.9459459 , which means that the LE set in variable $X_{1}$ and the $\mathrm{L}$ set in variable $Y$ load simultaneously. The same interpretation could be made for the subsequent rules until Rule 52. Rule 52 has the support value of 0.1250000 , which means that the general monthly inflation rate for Indonesia contains an LE set in variable $X_{1}$, L set in variable $X_{2}, \mathrm{~L}$ set in $X_{3}$, L set in variable $X_{5}$, L set in variable $X_{6}$, and LE set in $X_{7}$. It also contains an $\mathrm{L}$ set in variable $Y$. Meanwhile, the confidence is 1.0000000 , indicating that the data contains an LE set in variable $X_{1}$, L set in variable $X_{2}, \mathrm{~L}$ set in variable $X_{3}$, L set in variable $X_{5}$, L set in variable $X_{6}$, LE set in variable $X_{7}$, and L set in 
variable $Y$, simultaneously.

From Table 3 also, the lift ratio of Rule 1 is 1.967568, which means that its antecedent, variable $X_{l}$, contains an LE set and has a positive influence on its consequent, namely variable $Y$ which contains an $\mathrm{L}$ set. The same interpretation applies to the lift value ratio of all rules up to Rule 52. The lift ratio of Rule 52 is 2.080000 , which means that its antecedent, i.e. an LE set in variable $X_{1}$, L set in variable $X_{2}$, L set in variable $X_{3}$, L set in variable $X_{5}$, L set in variable $X_{6}$, and LE set in variable $X_{7}$, have a positive influence on its consequent, namely $\mathrm{L}$ set in variable $Y$.

The Mamdani method that was introduced by Ebraham Mamdani based on the research that was conducted Lotfi A. Zadeh using some IF-THEN rules which used fuzzy set as a rule consequent. Different from Mamdani method, Sugeno method that was introduced by Takagi-Sugeno-Kang uses mathematical function of the input as a rule consequent. The basic rule of the fuzzy inference system in the Mamdani method and zero-order Sugeno method is as follows: Rule $1=I F\left\{X_{1}\right.$ is LE $\}$ THEN $\{Y$ is L $\}$, up to Rule 52, where Rule $52=I F\left\{X_{1}\right.$ is $\mathrm{LE}\} A N D\left\{X_{2}\right.$ is $\left.\mathrm{L}\right\} A N D\left\{X_{3}\right.$ is $\left.\mathrm{L}\right\} A N D\left\{X_{5}\right.$ is $\left.\mathrm{L}\right\} A N D\left\{X_{6}\right.$ is $\left.\mathrm{L}\right\} A N D\left\{X_{7}\right.$ is LE $\}$ THEN $\{Y$ is $L$ \}.Meanwhile, the basic rule of the fuzzy inference system in the first-order Sugeno method used multiple linear regression as a linear equation.

$$
\begin{aligned}
\text { Inflation }_{L}= & -0,009+0,249 X_{1}+0,184 X_{2}+0,251 X_{3}+0,066 X_{4}+0,046 X_{5} \\
& +0,054 X_{6}+0,180 X_{7}
\end{aligned}
$$

$$
\begin{aligned}
\text { Inflation }_{L E}= & 0,023+0,233 X_{1}+0,158 X_{2}+0,237 X_{3}+0,072 X_{4}+0,038 X_{5} \\
& +0,065 X_{6}+0,150 X_{7}
\end{aligned}
$$

The adjusted R-squared value of 0.990 obtained from the multiple linear regression equation of L fuzzy set means that the diversity of the data can be explained by the regression equation of $99 \%$. Likewise, the value 0.976 for the adjusted R-squared derived from the multiple linear regression equation of LE fuzzy set means that the diversity of the data can be explained by the regression equation of $97.6 \%$. Based on the results of the testing parameters and adjusted R-squared values, it can be said that both regression equations obtained were feasible and could therefore be used as a system for the linear equations in the first-order Sugeno FIS in predicting inflation. After that, the implications of the application function were obtained by calculating the value of $\alpha$-predicate (fire strength) of each rule and the same steps were performed for the composition rules. Defuzzification was next performed on the testing data to obtain an output that would be used for the fitting.

The implication functions in the Mamdani and zero-order Sugeno methods use the minimum function by taking the smallest degree of membership value of the input variables. 


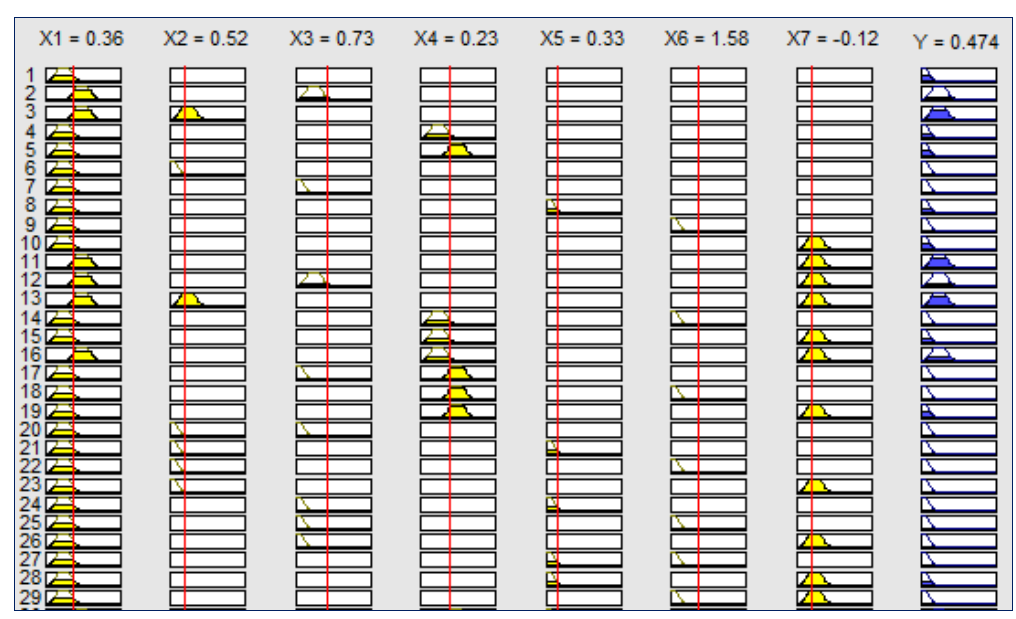

Figure 1. Result of defuzzification in Mamdani FIS

In order to obtain the results is shown in Figure 1, The composition of rules in Mamdani method use a max (maximum) method, In the max method the solution fuzzy set obtained by taking the maximum value of rule and then use it to modify the fuzzy area and apply it to the output by using the OR operator (Union). The first column shows the degree of membership of $X_{1}=0.36$, followed by $X_{2}=0.52$ for the second column, $X_{3}=0.73$ for the third column, $X_{4}$ $=0.23$ for the fourth column, $X_{5}=0.33$ for the fifth column, $X_{6}=1.58$ for the sixth column, and $X_{7}=-0.12$ for the seventh column; while the last column shows the consequent implications of the function in accordance with these conditions. Each column, from the $1^{\text {st }}$ to $7^{\text {th }}$ as well as the last one, shows the combined area of each fuzzy rule which is the consequent on the composition of the fuzzy rules. The defuzzification method used was the centroid defuzzification method.

The defuzzification result of Mamdani FIS is presented in Figure 1. The thick red vertical line through the variable of the common monthly inflation shows the predictive value of the magnitude of rate of the general inflation in the month of August 2014, which is 0.474.

In the zero-order Sugeno FIS, the composition of the rules derived from sum (summary) of collection and correlation between rules. The defuzzification was done using the Weighted Average method. Based on the deffuzification results, the predictive value of the magnitude of the general inflation rate for the month of August 2014 is 0.484 .

The Sugeno FIS has a similar result with the Mamdani FIS in the degree of membership of each variable. While the first-order Sugeno composition rules has the different method with the the Mamdani but produce relatively similar results. At the defuzzification stage, the weighted average method produced a little similar result as compared to the centroid methods by Mamdani fuzzy inference, in which the value of the magnitude of the general inflation rate obtained amounted to $0.469 \%$.

There were 31 testing data used in predicting the inflation rate, including data from February 2012 to August 2014. The application of the Mamdani FIS model for predicting the inflation rate was then compared with the actual data. The results of the Mamdani FIS in predicting the 


\section{Macrothink}

magnitude of the general monthly inflation rate is shown in Figure 2 below:

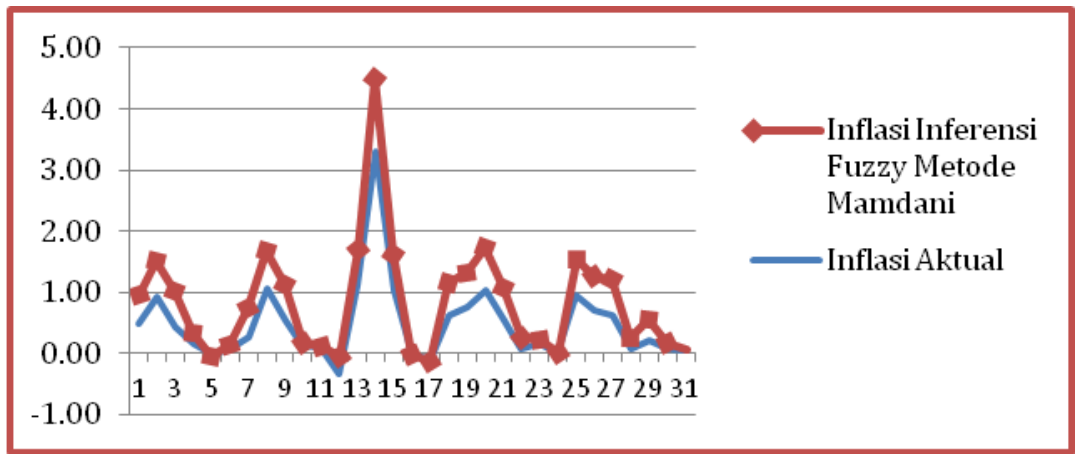

Figure 2. Graph of fitting model of the Mamdani fuzzy inference system for the inflation dat

The largest prediction error occurred in the data for July 2013 with the amount of 2.09, while the smallest prediction error occurred in the data for September 2013 with the amount of -0.64 .

The results of the zero-order Sugeno fuzzy inference method for predicting the magnitude of the general monthly inflation rate is illustrated in Figure 3. The largest prediction error occurred in July 2013th data while the smallest error occurred in September 2013th data with the readings of 2.72 and -0.46 , respectively.

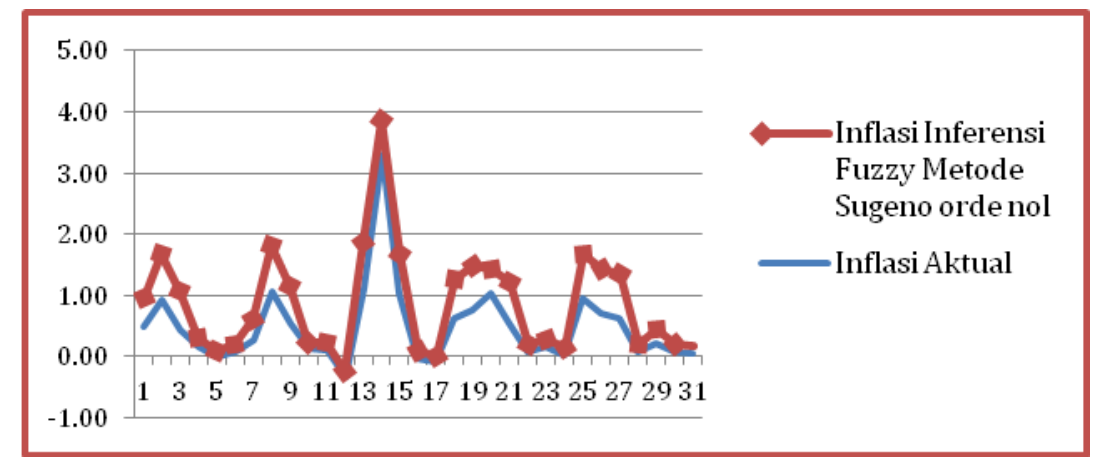

Figure 3. Graph of fitting model of the zero-order Sugeno fuzzy inference system for the inflation data

In Figure 4, while the result from the first-order Sugeno FIS in predicting the magnitude of the general monthly inflation rate shows that the largest prediction error occurred in the data for July 2013, which is 0.12 , the smallest prediction error occurred in the data for January 2014 with the amount of -0.07 . 


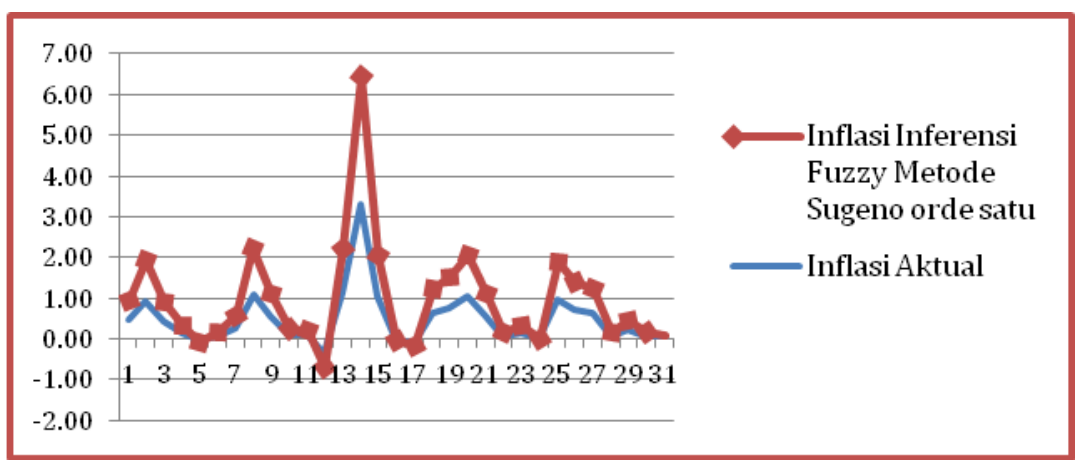

Figure 4. Graph of fitting model of the first-order Sugeno fuzzy inference system for the inflation data

The predictive values of Indonesia's general monthly rate were obtained from the calculation of the inflation rate's predicted value in the data testing system using the Mamdani and Sugeno FISs. These values were compared with the actual values of Indonesia's general monthly inflation rate. The measure of the accuracy of each prediction method was examined from the values of their MSE and MAPE.

Table 4. MSE and MAPE values of Mamdani and Sugeno methods

\begin{tabular}{|c|c|c|}
\hline Inference System & MSE & MAPE \\
\hline Mamdani's Fuzzy & 0,1927 & 0,6354 \\
\hline $\begin{array}{c}\text { Zero-order Sugeno's } \\
\text { fuzzy }\end{array}$ & 0,2801 & 0,9964 \\
\hline $\begin{array}{c}\text { First-order Sugeno's } \\
\text { fuzzy }\end{array}$ & 0,0012 & 0,2784 \\
\hline
\end{tabular}

As observed in Table 4, based on the comparison made between the three methods on the predicted values of Indonesia's inflation rate, the values of MSE and MAPE are as follows: 0.1927 and 0.6354, respectively, for the Mamdani FIS; 0.2801 and 0.9964, respectively, for the zero-order Sugeno FIS; and 0.0012 and 0.0012, respectively, for the first-order Sugeno FIS.

\section{Discussion}

The universe of discourse is the universe of all available information on a given problem (Ross, 2010). Each fuzzy variable that serves as the input is divided into five fuzzy sets, namely low fuzzy set, low-enough fuzzy set, medium fuzzy set, high-enough fuzzy set, and high fuzzy set. The classification of the fuzzy set in this study was based on the decision of the researcher. There was no special condition that formed the basis of determining the number of fuzzy sets for the researcher working on the fitting using fuzzy logic. The more 
fuzzy sets formed, the better the findings of the research.

The bell membership function has an extra parameter as compared to the Gaussian membership function. Although both these membership functions achieve smoothness, they are unable to specify asymmetric membership functions, which are important in certain applications (Mandal et al., 2012). This study used g-bell membership function with 5 memberships. Based on previous studies such as by Dewi (2012) on the forecasting of wind speed in Sumenep using adaptive neuro fuzzy inference system, Wijiyanto (2012) on forecasting contract value construction PT ' $\mathrm{X}$ ' using regression approach time series, and NFIS and Jamahir (2012) on the prediction of automobile warranty cost and warranty period using neuro fuzzy approach, it was found that the g-bell membership function is the best membership function based on the MSE value obtained in those studies, in which g-bell membership function gave the smallest MSE value as compared to the others such as the Gaussian and Trapezoidal membership functions.

Using a high value on the minimum support and the minimum confidence will only generate a few rules, while on the other side fuzzy inference system will generate accurate predictions if the system had a lot basis of rules that are being used and is in accordance with the character data. The rule-based feature has a strong influence on the FIS. Fewer number of rules being used will result in lesser combinations being generated, making the result of the prediction more inaccurate (Budhi, 2005). Due to these reasons, this study used the smallest values of minimum support and minimum confidence to obtain highly accurate results. Initially, 527 regulations were generated but after some adjustments were made to the rules of the FIS, the number was reduced to 52 .

The minimum value of the lift ratio was not specified as the support or confidence. The lift ratio values in Table 3 indicate that if the value is less than 1, the antecedent of the rule's consequent has a negative effect, and if the value is equal to 1 , the rules often occur together but independently. An independent rule is the process to obtain a consequent that does not depend on the antecedent. The rule recommended for the lift size ratio is that the ratio of its lift is more than 1 because, then, the antecedent of the rule has a positive influence on the consequent. A lift ratio also shows how important a set of rules that have been established are, based on the value of the support and confidence. An operating ratio is said to be valid if the lift is worth more than one (Chandra, 2010).

There were 5 multiple linear regression equations formed according to the number of fuzzy sets contained in the variables of the common monthly inflation, namely L fuzzy set, LE fuzzy set, M fuzzy set, HE fuzzy set, and $\mathrm{H}$ fuzzy set. However, only two fuzzy sets were constantly used, which is L and LE fuzzy sets, due to the fact that only these two sets appeared as consequents to the rules. Therefore, it is sufficient to only discuss the two fuzzy sets. 
Table 5. Comparison between Mamdani and Sugeno methods

\begin{tabular}{|c|c|c|c|}
\hline Methods & Antecedent & Consequent & Defuzzification \\
\hline Mamdani & Fuzzy sets & Fuzzy sets & Centroid \\
\hline Sugeno & Fuzzy sets & $\begin{array}{c}\text { Constant Linier } \\
\text { Equation }\end{array}$ & $\begin{array}{c}\text { Weighted } \\
\text { Average }\end{array}$ \\
\hline
\end{tabular}

A chart comparing the results of the general monthly inflation forecast of Indonesia using the Mamdani fuzzy inference method with the actual inflation has been shown in Figure 2. The results obtained from the Mamdani fuzzy inference method yielded quite different predictions from the actual values. In Figure 3, the data tested using the zero-order Sugeno method had almost similar results to that shown in Figure 2, in which the testing data were also quite different from the actual values. On other hand, different from the previous methods, the first-order Sugeno method shown in Figure 4 had better results that followed the actual values more closely.

The MSE and MAPE as precision measurements were used in determining which inference method best fits the results of the inflation data, with the results being presented previously in Table 4. Based on the MSE and MAPE, it was found that the first-order Sugeno FIS fitted better against the inflation data as compared to the Mamdani and zero-order Sugeno FISs. This can be seen from the MSE and MAPE values generated which were smaller for the first order Sugeno FIS as compared to the Mamdani and zero-order Sugeno FISs.

Furthermore, the results from the first-order Sugeno FIS was the best in fitting the inflation data due to the fact that the consequents of its fuzzy rules were in the form of multiple linear regression equations, while in the Mamdani method, the consequent rules were in the form of fuzzy sets only and in zero-order Sugeno, the consistent rules were in the form of constants.

Zufa (2013) had conducted a similar study of comparing the Mamdani FIS with the Sugeno FIS. The results of his research were similar to the results of this study, in which the best fitting result for the inflation data was the first-order Sugeno method, followed by the zero-order Sugeno method and the Mamdani method in terms of their accuracy.

\section{Conclusion}

Based on the discussion on the comparison between the Mamdani fuzzy inference system and the Sugeno fuzzy inference system, it can be concluded that:

1. 52 basic fuzzy rules have been generated when using the value 0.1058 and 0.800 as the size of the minimum support and minimum confidence respectively, in the method of Association Rules.

2. From the results obtained in this study, it can be seen that the graph with the best 
accuracy is the graph plotted based on the results of Sugeno first order fuzzy inference system.

3. Using the value of MAPE and MSE results of as the basis of comparison between the Sugeno Zero Order, Mamdani Fuzzy Interference System and the Sugeno First Order fuzzy inference system, it was found that the Sugeno First Order fuzzy inference systemis the most accurate method in predicting the monthly inflation data in Indonesia, as it has the smallest value of MAPE AND MSE as compared to the other two methods.

\section{References}

Budhi, G. S. (2005). Aplikasi Data Mining dengan Konsep c-Covering untuk Analisa Market Basket pada pasar swalayan. Surabaya: Petra.

Cox, E. (1994). The Fuzzy Systems Handbook (A Practitioner's Guide to Building, Using and Maintaining Fuzzy Systems). Massachusets: Academic Press, Inc. ISBN:0-12-194270-8.

Draper, N. R., \& Smith, H. (1992). Analisis Regresi Terapan Edisi Kedua. Jakarta: PT. Gramedia Pustaka Utama

Gao, J, Xu, X, \& He, C. (2012). A Study on the Control Methods Based on 3-DOF Helicopter Model. Journal of Computers, 7, 2526-33. http://dx.doi.org/10.4304/jcp.7.10.2526-2533.

Gopalan, R. P., \& Sucahyo, Y. G. (2004). High Performance Frequent Patterns Extraction using Compressed FP-Tree. Department of Computing, Curtin University of Technology. Australia.

Haman, A., \& Geogranas, N. (2008). Comparison of Mamdani and Sugeno Fuzzy Inference Systems for Evaluating the Quality of Experience of Hapto-Audio-Visual Applications. HAVE IEEE International Workshop on Haptic Audio Visual Environments and their Applications.

Hidayat, I. (2010). Analisis Pengaruh Harga Bahan Bakar Minyak Eceran dan Industri Terhadap Indeks Harga Kelompok Komoditi Pembentuk Indeks Harga Konsumen di Indonesia. Jakarta. Thesis of Master, Faculty of Economy, Universitas Indonesia.

Kaur, A., \& Kaur, A. (2012). Comparison of Mamdani-type and Sugeno-type Fuzzy Inference Systems for Air Conditioning System. International Journal of Soft Computing and Engineering, 2(2), May 2012. ISSN: 2231-2307.

Mohandas, K., \& Karimulla, S. (2001). Fuzzy and Neuro-Fuzzy Modeling and Control of Non Linear Systems.Second International Conference on Electrical and Electronics.

Naba, A. (2009). Belajar Cepat Fuzzy Logic Menggunakan Matlab. Yogyakarta: Penerbit ANDI. ISBN: 9789792909319.

Ross, T. J. (2009). Fuzzy logic with Engineering Applications: John Wiley \& Sons.

Sandhu, G. S., \& Rattan, K. S. (1997). Design of A Neuro-Fuzzy Controller. Systems, Man, 
and Cybernetics, Computational Cybernetics and Simulation. IEEE International Conference on: IEEE. pp. 3170-3175, vol 4. http://dx.doi.org/10.1109/ICSMC.1997.633083.

Setiadji. (2009). Himpunan dan Logika Samar serta Aplikasinya. Yogyakarta: Graha Ilmu. Online Access: http://catalog.uinsby.ac.id//index.php?p=show_detail\&id=75322.

Song, Z, Song, X, Liu, C., \& Zhao, Y. (2013). Research on Real-Time Simulation and Control of Linear 1-Stage Inverted Pendulum. Journal of Computers, 8(4), 896-903. doi:10.4304/jcp.8.4.896-903.

Sugeno, M., \& Kang, G. (1988). Structure Identification of Fuzzy Model. Fuzzy Sets and Systems, 28, 15-33.

Susilo, F. (2003). Pengantar Himpunan Kabur dan Logika Kabur Serta Aplikasinya. Yogyakarta: Universitas Sanata Dharma.

Takagi, T., \& Sugeno, M. (1985). Fuzzy Identification of Systems and its Applications to Modeling and Control.Systems, Man and Cybernetics. IEEE Transactions, 15(1), 116-32. http://dx.doi.org/10.1109/TSMC.1985.6313399.

Utomo, I, P. (2010). Penerapan Fuzzy c-Covering pada Transaksi Belanja Mini Market. Jakarta: UPN Veteran

Wang, Y., \& Chen, Y. (2014). A Comparison of Mamdani and Sugeno Fuzzy Inference Systems for Traffic Flow Prediction. Journal of Computers, 9, 12-21. http://dx.doi.org/10.4304/jcp.9.1.12-21.

Zhao, G, Shen, Y, W., \& Wang, Y. (2013). Fuzzy PID Position Control Approach in Computer Numerical Control Machine Tool. Journal of Computers, 8(3), 622-629. DOI: $10.4304 /$ jcp.8.3.622-629.

Zufa, F. (2013). Perbandingan Sistem Inferensi Fuzzy Metode Mamdani dan Metode Sugeno Dalam Memprediksi Laju Inflasi. Jurnal Mahasiswa, Universitas Brawijaya, Malang, 1(4), 297-300.

Online

Access:

http://statistik.studentjournal.ub.ac.id/index.php/statistik/issue/view/4

\section{Copyright Disclaimer}

Copyright for this article is retained by the author(s), with first publication rights granted to the journal.

This is an open-access article distributed under the terms and conditions of the Creative Commons Attribution license (http://creativecommons.org/licenses/by/3.0/). 